\title{
VARIA
}

\section{LA SEGUNDA EPÍSTOLA DE ALFONSO DE VALLADOLID}

La excelente formación bíblica, talmúdica y exegética recibida durante sus años de aprendizaje rabínico le sirvió al médico judío Abner de Burgos (ca. 1270 - ca. 1346) para, después de su bautismo cristiano como Alfonso de Valladolid y su enrolamiento en las filas del antijudaísmo militante ', escribir una nutrida serie de tratados de controversia religiosa que culmina en el exhaustivo y eruditísimo Libro mostrador de justiçia ${ }^{2}$. Esta summa antijudaica, acabada en torno a 1325-1330, le serviría de fuente para otras obras de menor alcance, como el tratado Těsubôt la-mĕharef («Respuestas al blasfemo»), donde ataca la defensa racionalista del judaísmo emprendida, en contra del propio Alfonso, por su exdiscípulo Isaac ben Polgar. La misma intención polémica se manifiesta en sus tres epístolas, donde aborda de forma abreviada temas doctrinales típicos de la controversia cristiano-judía bajomedieval ${ }^{3}$.

Las tres epístolas de Abner se conservan, en castellano, en el manuscrito "Latinus 6423" de la Biblioteca Vaticana y, en hebreo, en el Sefer Alfonso («Ms. 2440»/«De Rossi 533») de la Biblioteca Palatina de Parma; ambos códices datan de la segunda mitad del siglo XIV ${ }^{4}$. La segunda de estas cartas, como sus compañeras,

${ }^{1}$ Sobre el autor, esencial para la comprensión del entramado social y cultural de la "España de las tres religiones", cf. la bibliografia a que se remite en nuestro "La Epístola Tercera de Alfonso de Valladolid", Anuario Medieval II (1990) pp. 7-22, a la que puede añadirse C. SAINZ DE LA MAZA, "Apuntes para la edición del tratado Contra las hadas atribuido a Alfonso de Valladolid (Abner de Burgos)", Incipit [en prensa].

${ }^{2}$ Folios $12 \mathrm{r}-342 \mathrm{v}$ del manuscrito "Espagnol 43" de la Bibliothèque Nationale de Paris; cf. E. DE OCHOA, Catálogo razonado de los manuscritos españoles existentes en la Biblioteca Real de Parts, Paris 1844, pp. 26-28. W. Wettmann da una idea precisa de su contenido al editar su detalladísimo sumario (fols. 13v-28r) en Die volkssprachliche apologetische Literatur auf der Iberischen Halbinsel im Mittelalter, Opladen 1987, pp. 41-75.

${ }^{3}$ Sobre la epístola como vehículo literario y de ideas entre los judíos, cf. nuestro art. cit. en la nota 1.

${ }^{4}$ El castellano cuenta con la ed. de C. SAINz DE LA MAZA, Alfonso de Valladolid: edición y estudio del Ms. "Lat. 6423" de la Biblioteca Apostólica Vaticana, Madrid 
resulta de difícil datación: conocemos el nombre de su destinatario, cierto "sabio amigo R. Mosé el Hazán», pero la identidad de éste es, de nuevo, problemática s.

La discusión de los contenidos mesiánicos de Daniel, tema común de las epístolas, se centra aquí en el problema de la interpretación de la cronología danielina. El sugestivo dramatismo de las visiones apocalípticas atribuidas a Daniel, que ya en la antigüedad había servido de estímulo a la especulación sobre el fin de los tiempos y la era mesiánica ${ }^{6}$, atrajo también a los padres del cristianismo, pąando a ser obligada su interpretación cristológica a partir de los comentarios de San Jerónimo ?. Sin embargo, por parte judía, los rabinos procuraron que la controversia acerca del tema ocupase un lugar secundario en la actividad exegética, como pone de manifiesto la conocida maldición de Sanh 97b: "Que se les sequen los huesos a los que calculen el final de los tiempos» ${ }^{8}$.

1990. Las versiones hebreas de las epístolas fueron editadas por J. M. Rosenthal, "From Sefer Alfonso", en Studies and Essays in Honor of A. A. Neuman, Leiden 1962, pp. 588-621; "The Second Epistle of Abner of Burgos", en The Abraham Weiss Jubilee Volume, N. York 1964, pp. 483-510; "The Third Epistle of Abner of Burgos", en Studies in Bibliography and Booklore 5 (1961) sección hebrea, pp. 42-51.

${ }^{5}$ Rosenthal sugiere en su edición la posibilidad de que se trate de R. Mošeh Natan de Tárrega (cuyo nombre sefardí es Azán), cortesano y comerciante, poeta en hebreo y catalán, y personaje prestigioso de la judería catalano-aragonesa. Cercano al partido anti-filosófico, apoyó hacia 1360 el movimiento de reforma religiosa impulsado en Barcelona por R. Nissim b. Reuben Girondí. La propuesta de Rosenthal, aunque sugestiva, no tiene en cuenta la tal vez excesiva diferencia de edad entre Alfonso y R. Mošeh. Sobre éste, cf. Y. BAER, Historia de los judíos en la España cristiana, Madrid 1981, I, pp. 326 y 334. En todo caso, quien contestó a las epístolas de Abner no fueron sus destinatarios, sino el matemático R. Yosef Salom; sus respuestas se incluyen en las ediciones citadas de Rosenthal.

6 Además de lo que dice Rosenthal en su ed. de la epístola, cf. S. W. BARON, Historia social y religiosa del pueblo judío, II: Época antigua, 2." parte, B. Aires 1968, pp. 67-71; R. J. Z. WeRBLOWSKY, "Messianism in Jewish History", Cahiers d'Histoire Mondiale 11 (1968) pp. 30-45; H. H. Ben-SASsON, «Messianic Movements», Encyclopaedia Judaica, Jerusalem 1971, XI, cols. 1420-1421.

7 Cf. J. P. Migne (ed.), S. Jerónimo: Comentaria in Danielem. Patrologia Latina, XXV, cols. 491-584, passim (cf., por ejemplo, Dn 9,24 «Nullique dubium quin de adventu Christi praedicatio sit, qui post septuaginta hebdomadas mundo apparuit...»).

${ }^{8}$ Ejemplos medievales de las prevenciones rabínicas respecto al tema de la venida del Mesías, redobladas con el aumento de la agresividad misionera cristiana a partir del siglo XIII, los tenemos en la actitud de Nahmánides en la controversia de Barcelona de 1263 y de los rabinos participantes en la de Tortosa de 1413 (cf. Y. BAER, Historia, I, p. 124 y II, pp. 454 ss.), al señalar que la cuestión mesiánica no era central para el judaísmo. El propio Abner de Burgos acusa en Respuestas al blasfemo a Isaac ben Polgar de defender «que la fe de los judíos non es decolgada 
Lo cierto es que las interpretaciones y predicciones basadas en la cronología apocalíptico-mesiánica son frecuentes en la obra de los sabios judíos de la Edad Media, y que la perspectiva de la inminente llegada del Mesías inflamó más de una vez la imaginación popular de las comunidades, tanto en tierras orientales, bizantinas o islámicas, como en los reinos cristianos occidentales, y en especial en los momentos de mayor deterioro de la convivencia con los grupos mayoritarios musulmán y cristiano. El deseo judío de trascender la desfavorable situación histórica de la Diáspora llevó a una continua transgresión de las prohibiciones rabínicas durante todo el medioevo y a la consiguiente serie de predicciones fracasadas ${ }^{9}$.

En su epístola, Abner-Alfonso examina las referencias cronológicas incluidas en Dn 8,13-14 y 26; 9,24-27; y 12,11-12. Recurre a la exégesis literal de base gramatical y lógica para desechar las interpretaciones de Raši y Yosef Qimhi y propone sus propios plazos, insistiendo en el valor cristológico de la profecía danielina de las setenta semanas (Dn 9,24 y ss.). El texto se cierra rebatiendo la idea, tomada de Dn 12,8 , de que el autor bíblico no comprendía su propia visión: ¿cómo, en tal caso, habría podido escribir sobre ella? ${ }^{10}$.

Las fuentes utilizadas por el autor son un buen ejemplo del aprovechamiento de la literatura rabínica por parte de los polemistas antijudíos bajomedievales. Alfonso de Valladolid recurre, naturalmente, a la Biblia, y también al Talmud (Sanhedrin) y a algunos pasajes midrásicos (Rut Rabba, Leqah Tob, Midraš de los diez reyes). Pero sus auctoritates favoritas son los propios sabios judíos de la Edad Media: Sěcadyah Ga’on, Ibn Ŷanah, Abraham bar Hiyya,

en la venida de Christo, [lo qual] es prueva contra ti de la raíz de tus palabras que tú mismo baruntas la flaqueza de tus razones sobre la venida del Christon (fol. 63rb, Ms. Vaticano "Lat. 6423"; ed. cit., p. 613). A despecho de tales actitudes defensivas, como muy bien resume H. H. BEN-SASSON, "Up to the 18 th. century it was both an article of faith and an emotional necessity among Jews to hope constantly for the immediate advent of Messiah" (art. cit., col. 1417).

9 Sobre el interés de sabios y pueblo judíos por el tema en la Edad Media, cf. S. W. BARON, op. cit., V, pp. 137-205; R. J. Z. WERBLOWSKY, art. cit., pp. 3940; H. H. BEN-SASSON, art. cit., cols. 1422 ss.

${ }^{10}$ En esta ignorancia insistirá la respuesta de Yosef Salom, que también reprocha a Alfonso de Valladolid su método de basarse en citas fragmentarias (método, por otra parte, usual entre los comentaristas bíblicos y talmúdicos). Cf. el prólogo a la edición de Rosenthal y Y. SHAMIR, Rabbi Moses ha-Kohen of Tordesillas and His Book «Ezer ha-Emunah», Leiden 1975, pp. 57-58 y 60-61. 
Abraham ibn Daud, Abraham ibn Ezra y Nahmánides ", quienes cubren un amplio repertorio de actividades intelectuales, de la gramática a la historia y de la filosofia a la exégesis esotérica. El conjunto ofrece un muestrario breve pero elocuente de la erudición rabínica del autor que, por otra parte, trata de los mismos temas de un modo mucho más detallado y abrumador en los capítulos VII y VIII del Mostrador de justiçia ${ }^{12}$.

Editamos a continuación el texto castellano de la segunda epístola de Alfonso, conservado en el manuscrito vaticano "Latinus 6423" (fols. 92ra-97ra), junto con la traducción de la versión hebrea medieval del manuscrito "Ms. 2440" de Parma ${ }^{13}$, así como un glosario que recoge los términos más interesantes del romance empleado por el autor, lleno de resonancias semíticas tanto léxicas como sintácticas. Ambas versiones, que no están genéticamente relacionadas, revelan a veces en sus divergencias que fueron redactadas teniendo en cuenta las posibles diferencias de formación de sus respectivos lectores virtuales: rabinos judíos en un caso, clérigos interesados por la controversia doctrinal en el otro.

\section{Epístola II $^{14}$}

$\mathrm{E}[\mathrm{t}]$ esta es la [Epistola] ${ }^{15}$ segunda:

Et dixo Maestre Alfon[so]: Ruégote, el sabio amigo Rabí Mosé el

11 Éste habría sido el maestro del propio Abner-Alfonso, según la leyenda recogida por el judío italiano Gědalyah ben Yosef ibn Yahya (1515-1578) en su Šalselet haQabbalá. La rechaza ya H. GRAETZ, Geschichte der Juden, Leipzig 1860-1878, VII, p. 509. Rosenthal cree que se trata de una posible confusión entre Abner y Pablo Christianus, el adversario de Nahmánides en 1263 (cf. "The Second", p. 484 y n. 12). La leyenda, de todos modos, es un indicio del prestigio alcanzado por el saber rabínico de Alfonso entre los propios judíos.

${ }^{12}$ Cf. cap. VII, parágrafo $7^{9}$, sobre los cálculos mesiánicos; en los caps. VII y VIII abundan los materiales de discusión acerca del Mesías. Cf. también Respuestas al blasfemo, cap. V, especialmente fols. 67vb-75rb (ed. cit., pp. 625-643).

${ }^{13}$ Seguimos con algunas modificaciones la ed. cit. de C. SAINZ DE LA MAZA, pp. 739-758, para el texto castellano. La traducción del texto hebreo se basa en la edición de Rosenthal.

14 Adoptamos el siguiente criterio editorial: se moderniza la distribución gráfica de $\mathrm{i} / \mathrm{j}, \mathrm{u} / \mathrm{v}, \mathrm{y} / \mathrm{i}$; simplificación de dobles consonantes iniciales y dobles consonantes no etimológicas, a excepción de -s- y -ss- intervocálicas; la tilde sobre $\mathrm{m}, \mathrm{n}$, se resuelve como $\mathrm{mm}$, $\mathrm{nn}$; se mantienen los frecuentes trueques gráficos del copista entre $1 / 11, n / n n, r / r r$, aclarando en nota posibles ambigüedades de sentido; el signo tironiano se transcribe como «et». Se modernizan los acentos y la puntuación. Las enmiendas y adiciones al texto se indican entre corchetes.

15 El manuscrito V. abbr.: spla. 
Hazán, que studies en lo que es scripto en el Libro de Daniel: «Oí un sancto fablante et dixo al fullano fablante: "¿Fasta quándo la propheçía et el sacrifiçio et el pecado assollado, dar et santidat et conpanna folladura?". Et dixo a mí: "Fasta bíspera et mannana dos mil et .CCC., et será justificada santidat" " ${ }^{16}$. Et splanó Rabí Salamón de Troyas ${ }^{17}$ fasta quándo se conplirá esta propheçía, que fue sobre el sacrifiçio de cada día para ser tollido et que el pecado de assollamiento sea dado en su logar; ca el vierbo 'assollado' quiere dezir segund el ebraico 'en este logar callado', ca lo dize por el ídolo, que es mudo [92rb] et callado como piedra, que avía a ser dado et puesto en el templo, et que lo que $\operatorname{dix}[0]$ "dar et santidat et conpanna folladura» quiere dezir 'para dar al santuario et la conpanna del çiello que echó a tierra que sean folladura de sus pies'. Et dixo que aquella letra 'et' que era conjunçión en el vierbo "et santidat", dize que es de más y que assí suelle ser en el ebraico letras de conjunçiones de más; et que lo que dixo después "fasta bíspera et mannana", que es dicho segund el ebraico 'héreb bóquer' ${ }^{18}$, es dicho por cuento de letras, non por dezir 'bíspera et mannana'. Et dixo que lo prueva esto por dos razones: la una raçón, porque sea este cuento conçertado con el cuento que es dicho en fin del libro «días mil et .CC. et ${ }^{19}$ noventa" ${ }^{20}$, que quier dezir 'mil et .CC. et noventa annos'; et la razón segunda, porque dixo el ángel Gabriel a Daniel: «Vissión de la bíspera et la mannana que fue dicha, verdat es" ${ }^{21}$, ca si la significanza del cuento et la su raíz no fuesse decolgada en aquellos vierbos 'bíspera et mannana', ¿por qué tornaría a doblar la palabra et dezir "verdat es»?

Et aquellos vierbos 'héreb bóquer', segund lieva el cuento de las sus letras en el ebraico, montan quinientos et setenta et quatro; ayuntá[n]dolos a los dos mil et .CCC. que son paladinos en el viesso montarán dos mil et ochoçientos et setenta et quatro, y éste es el cuento de los annos que son desde la catividat de Egipto fasta la venida del Christo, et son contados en esta guisa: dozientos et diez de la catividat de Egipto [92va] et quatroçientos et ochenta después fasta el frauguamiento del Templo primero, et después quatroçientos et diez que stido poblado el Templo, et después setenta que estido desertado, et después quatroçientos et quatorçe que duró el Templo segundo fasta la ora que fue tollido el sacrifiçio de cada día, ca el sacrifiçio de cada día fue tollido seis annos ante del desertamiento, montan estos mil et quinientos et ochenta

${ }^{16}$ Dn 8,13-14. La puntuación, conjetural, pretende adaptar la peculiar versión de Alfonso a los sentidos dados por las traducciones actuales más autorizadas (la española de F. Cantera, la inglesa de la Soncino Press, etc.).

17 Raši a Dn 12,11.

${ }^{18}$ Héreb bóquer, "noche-día".

19 Vírgula y no signo tironiano.

${ }^{20}$ Dn 12,11 .

${ }^{21}$ Dn 8,26. 
et quatro; ennadeldes mil et dozientos et noventa que son desde la ora que fue tollido el sacrifiçio de cada día fasta la venida del Christo, montarán dos mil et ochoçientos et setenta et quatro como dicho es.

Et dixo este glossador ${ }^{22}$ que non tenemos prueva manifiesta de aquellos seis annos, sino que los tomó porque venga este cuento conçertado con el cuento que es dicho en fin del libro, et que los llamó el viesso a aquellos seis annos 'media selmana', que es tres annos et medio, en lo que dixo: «La media selmana toldrá sacrifiçio et ostia» ${ }^{23}$, porque non fue selmana conplida.

Et aún algunos glossadores enadieron en el vierbo 'bóquer' una letra vocal que nonbran ellos 'vav' por mester de aquellos seis annos ${ }^{24}$.

Et segund esto será el tollimiento del sacrifiçio de cada día a la fin del desertamiento, y el vierbo que dize «días mil et .CC. et noventa» es como annos; ca assí dize tal vierbo en el libro Levítico: «Días será su redenpçión" ${ }^{25}$, que quiere dezir 'annos', et assí [92vb] dize en el Libro [de los Jueçes] 26: "De día a día», que quiere dezir 'anno'.

Et entonçe se cunplieron los dos tienpos et medio que son nonbrados en el viesso que dize: "Ca a tienpo de tienpos et medio" ${ }^{27}$; ca el vierbo que dize «a tienpo" es ministrador, assí como otro viesso que dize: "A tienpo del mes tenprano" ${ }^{28}$. Et que el cuento es dos tienpos et la meatad de aquellos dos tienpos, los quales el un tienpo d'ellos es los quatroçientos et ochenta annos que ovo desde que sallieron de Egipto fasta el frauguamiento del Tenplo primero; et que el tienpo segundo fue los quatroçientos et diez annos que ovo del frauguamiento del Tenplo primero fasta su desertamiento. Montan los dos tienpos ochocientos et noventa annos, et la meatad d'estos dos tienpos es quatrocientos et quarenta et çinco; montará todo mil et .CCC. et treinta et çinco annos ${ }^{29}$.

22 Es decir, Raši.

${ }^{23}$ Dn 9,27 .

${ }^{24}$ B. KenNikotT, Vetus Testamentum Hebraicum cum variis lectionibus, II, Oxford 1776-1780, p. 597.

${ }^{25} \mathrm{Lv} 25,29$.

${ }^{26}$ Cf. W. BACHer (ed.), Yonah ibn Y̌anah: Sefer ha-šorašim, Berlin 1896, p. 196.

${ }^{27}$ Dn 12,7 (o 7,25).

${ }^{28}$ Ex 23,15 , donde se habla del mes de $A b i b$, primero del calendario judío, en primavera. Sobre su traducción en las distintas Biblias romanceadas judeo-cristianas, cf. L. Amigo, El Pentateuco de Constantinopla y la Biblia Medieval Romanceada Judeoespañola. Criterios y fuentes de traducción, Salamanca 1983, p. 77; así la Biblia escurialense E7 explica "tenprano, que es el mes de março». Rosenthal remite a Ibn Ezra en el comentario a Dn 12,11.

${ }^{29}$ Rosenthal indica que la última parte falta en Raši a Daniel y remite a Raši a Sanh 97b, donde comenta Dn 7,25: “un tiempo, los cuatrocientos años de esclavitud en Egipto; con otros dos tiempos y medio, suman mil cuatrocientos años". 
Et Rabí Yuçef Canhí ${ }^{30}$ splanó que quería dezir 'tienpo de tienpos et la meatad de aquel tienpo', segund que es dicho en el ebraico "Rey de reyes" ${ }^{31}$ et "Prínçipe de prínçipes" ${ }^{32}$, que quiere dezir 'el mayor de los reyes' et 'el mayor de los prínçipes'; et assí aquí quiere dezir 'el mayor de todos los cuentos', que es mil, et la mitad de mil es quinientos, como que dize 'mil et quinientos annos'; y que se cuenta del regno de Antíocho, rey de Yaván ${ }^{33}$, que fue a la meatad del tienpo del Tenplo segundo después de dozientos et diez annos; si los ayun[93ra]táredes a lo[s] an[n]os de la catividat, que son mil et dozientos et noventa, montarán mil et [quinientos] ${ }^{34}$ annos como dicho es.

Et paréceme a mí que no son nada todas estas glossas, ca no conviene a dezir que nonbrasse el viesso a ninguna cossa cuento de annos o de días de sin que nonbrasse paladinamente comienço terminado donde començase aquel cuento. Et más, ¿cómo sería el comienço del cuento de víspera et mannana dos mil et .CCC. desde la catividat de Egipto, non seyendo la catividat de Egipto no[n]brada en ningún logar de aquella propheçía? Et demás, seyendo el otro cuento, segund ellos tienen, començado de otro comienço que es la sallida de Egipto; et segund Rabí Yuçef Camhí començó d'otro comienço, que fue el regno de $\mathrm{A}[\mathrm{n}] \mathrm{tí}$ och[o] ${ }^{33}$, et non nonbrando en el viesso ni catividat de Egipto, ni sallida de la catividat de Egipto nin regno de Antíocho.

Et más, ¿cómo convernía a ser una partida del cuento dicho paladinamente, que es dos mil et .CCC., et la otra partida dicho en significanças encobiertas segund el cuento de las letras 'héreb bóquer', que tienen que es quinientos et setenta et quatro, et por qué no sería el cuento todo dicho palladino o todo dicho en significança? Et más, que aunque fuesse aquello significança de cuento como ellos diçen, pues luego non finca de quál será el subj [93rb] ecto contado de aquel cuento que era dos mil et ochoçientos et setenta et quatro, et non sería sabido si es cuento de an[n]os o de meses, o de días o setenarios de annos, o de jubileos ${ }^{36}$. Et aunque dixiéssedes que los vierbos 'víspera et mannana' abondan para amas las dos cossas, para la forma del cuento segund son puestas las letras en el alfabeto et para el subjecto del cuento segund la razón que muestran los vierbos en la lengua

\footnotetext{
${ }^{30}$ No localizable, como confirma Rosenthal; quizás pertenecía a la parte boy perdida del Sefer ha-Berit.

${ }^{31} \mathrm{Ez} 26,7$.

${ }^{32}$ Dn 8,25.

${ }^{33}$ El rey seléucida Antioco IV Epifanes (176-164 a. C.). Rosenthal remite a Gersónides a Dn 8.

${ }^{34}$ V.: dozientos.

35 V.: atiocha.

${ }^{36}$ Un jubileo abarca cincuenta años; cf. Lv 25,8-12.
} 
del ebraico, sería el cuento segund esto cuento de días, que es bíspera et mannana cada día, non cuento de annos segund ellos tienen; et sería esto prueva de que ya es passado el tienpo de la venida del Christo et sería esto dessatamiento de sus dichos d'ellos.

Et más, que el viesso que dize: "Vissión de la bíspera et la mannana que es dicha, verdat es" ${ }^{37}$, da a entender paladinamente que no es significança encubierta nin cuento de letras; ca si, eso fuesse, oviera el viesso a dezir al contrario de lo que dixo, et que dixiesse assí: 'La vissión de la bíspera et la man que fue dicha no es verda[t]'. Ca quando la palabra no fuere entendida segund su istoria llana será no verdadera; et no es mester de dezir "verdat es" por la entençión primera que es entendida del viesso, sinon que lo dixo aquí que era verdat por mostrar que no ha otro meollo encubierto, ni que es metháfora ni significança encubierta para que oviesse mester [93va] glosa como fue mester glosa a las otras cossas que fueron dichas en aquella vissión; ca dixo: «El carnero que viste de los dos cuernos es dicho por los reyes de Media et de Persia» 38; et lo que dixo: «El morrueco cabrón es dicho por el rey de Yaván» ${ }^{39}$; et assí lo que dixo: «Por el cuerno pequeno creçentó fasta la conpanna del çiello, et echó a tierra de la conpanna del çiello et echó a tierra de la conpanna et de las strelas et follólas» ${ }^{40}$, et dixo por splanar esto: «Levantarse á rey fuerte de façes y entendedor de palabras encubiertas. Y enfortezerse á su virtud et non por su virtud misma; et maravillas cofondrá et prevalezrá et fará, et confondrá fuertes et pueblo de los santos" ${ }^{41}$.

Et porque bíspera et mannana es raçón de un día, segund dixo el viesso: "Fue víspera et fue mannana: día uno" ${ }^{42}$, et que el vierbo 'bíspera' en este logar es arrimado a 'mannana' segund el ebraico, como que dize «bíspera de mannana" ${ }^{43}$, et que podría alguno cuidar que assí como 'días' es dicho en el ebraico por 'anno', assí "bíspera de man» es dicho en este logar por significança de 'anno' o de otro tienpo o de otra razón, así como las otras palabras d'aquella propheçía significan otras razones, por esto splanó el viesso et dixo: "Verdat es", que quiere dezir que es verdat segund su istoria llana bíspera de mannana verdaderamente, de sin que aya otra glossa $o$ otra soltura. Y esto, segund dixo en el capítulo onzeno: "Agora verdat anunçiaré a ti» ${ }^{44}$, que quiere dezir que'l diría fechos de los reyes de Persia

${ }^{37}$ Dn 8,26 .

${ }^{38}$ Dn 8,20 .

${ }^{39}$ Dn 8,21. Yaván es el reino helenístico seléucida.

${ }^{40}$ Dn 8,10 .

${ }^{41}$ Dn 8,23-24.

${ }^{42}$ Gn 1,5 .

${ }^{43}$ Prov 7,9.

44 Dn 11,2. Esta referencia falta en la versión hebrea. 
et de Yaván paladinamente, non por significanzas de [93vb] ángeles, nin de bestias, [n]in de cuerpos, nin de alas. Et assí dixieron en el libro Megilla ${ }^{45}$ que la palabra que es dicha por metháfora no es verdadera, et que la que es verdadera non es significança. Et por ende, pues que dixo el viesso: «Verdat es", muestra sin dubda que no es metháfora nin significança encubierta como dizían aquellos glossadores; et más, que ellos mismos otorgaron que non tienen prueba manifiesta de aquellos seis annos de que dixieron que fue tollido el sarifiçio de cada día en ellos ante del desertamiento, más aún, ante dize en el libro Çéder cabalá ${ }^{46}$ el contrario d'esto, que el sacrificio de cada día fue tollido ante del desertamiento mil et .CC. et noventa días, et que por esso dixo el viesso: "Desde la ora que fue tollido el sacrifiçio fasta dar el enconamiento assollado, días mil et .CC. et noventa" ${ }^{47}$; y aquellos son tres an[n]os et medio que eran la media selmana de que dixo el viesso por ella: "A la media selmana toldrá sacrifiçio et ostia» ${ }^{48}$, et segund esto sería aquel tienpo de salvaçión a la fin del desertamiento del Tenplo.

Et más, que el vierbo 'yamim' non es dicho en el ebraico segund la istoria por muchos annos como lo tienen aquellos glosadores, mas es dicho por muchos días o por un anno, porque es el anno retorno et revoluç[i]ón [94ra] de los días segund sus naturas et sus quantidades; et como dixo el viesso: "Fasta conplirse anno de su venida; días será su redenpçión" "49, que quier dezir 'un anno'; et así dixo otro viesso: "De días a días" so, que quier dezir 'de anno a anno'. Et así scrivió el gramático Rabí Yhoná ben Janaha ${ }^{51}$ que 'yamim' es pluralidat de 'yhom', que quier dezir 'días' o que es 'un anno', et que la su pluralidat deve ser dicha en el ebraico 'yeminim', como dizen de 'tamim', 'tami[m]im' ${ }^{52}$. Et assí scrivió Rabí Abraham ben Ezdra ${ }^{53}$ que quando es nonbrado en el ebraico el vierbo 'yamim' de sin ningund cuento será dicho por un anno; et que lo que dize el viesso: "Yamim mil et dozientos et noventa", es dicho por días et no por annos, et que quiere dezir 'días mil et dozientos et noventa', que montan tres annos et medio, assí como dize en el libro Heliahu Rabd ${ }^{54}$ sobre el viesso que dize: "Tienpo

${ }^{45}$ No en Meg, sino en Sanh $92 b$ (referencia a 1 Sam 2,6).

46 Abraham ibn Daud: Sefer ha-Qabbala, ed. y trad. G. C. CoHEN, Londres 1969,

I, p. 14 (líns. 200-204).

47 Dn 12,11 .

48 Dn 9,27.

49 Lv 25,29.

so Jue 11,40 .

${ }^{51}$ Como supra, nota 26.

52 V.: tamimim. En heb. Tamim (těmimim): 'perfecto, entero, sincero'. Cf. Num 28,31 .

${ }^{33}$ Cf. Abraham ibn Ezra, comentario breve a Daniel, especialmente 12,11.

54 Atribución falsa; se encuentra, en realidad, en el midraš de los diez reyes, publicado en D. EISENSTEIN, Osar midrašim, s. 1. 1969, II, p. 466. 
et tienpos et medio tienpo" 55 que "tienpo" es 'un anno' et "tienpos" es 'dos annos' et "medio tienpo" es 'medio anno'; montan estos tres annos et medio. Et assí splanó Rabeno Çahadias ${ }^{56}$ que lo que dize: "Tienpo et tienpos et medio tienpo» en la lengua ebraica dízelo por el cuento mismo del fondón del libro, que dize: "Días mil et dozientos et noventa" ${ }^{57}$. Et assí dize en la glossa del Libro de $R u{ }^{58}$ por aquellos días, que aquellos días de más que cuenta el un viesso sobre el otro, que por qué son, et responde que son quarenta et çinco días en que será el Salvador encubierto; et otros ${ }^{59}$ dixieron que son quarenta et çinco días desde el día que fue muerto el Christo fijo de Josep fasta la venida [94rb] de Christo fijo de David.

Et assí Elía et Rabí Haquiva et Rabí Osúa ben Leví et Rab et otros grandes sabios ${ }^{60}$ dieron para la venida del Christo tienpos terminados que son ya conplidos et passados, et no lo pudieron dezir assí si entendieran que aquel vierbo 'yamim' fuesse dicho por 'annos'; ca aún en aquel tienpo non eran pasados desde la ora que fue tollido el sacrifiçio de cada día mil et dozientos et noventa annos, et no conviene a dezir que los judíos saben agora de la lengua ebraica más que lo que sabían d'ella los sabios del Talmud, que eran çercanos del tienpo de los prophetas et que d'ellos tienen lo que agora saben d'él.

Et más, que el vierbo 'tienpo' de lo que dize el ebraico: “Ca ha tienpo et tienpos et medio" "61 no es ministrador como lo dezían aquellos glosadores, porque sobre esso dixo en el caldeo: "Serán dados en su mano fasta tienpo et tienpos et medio tienpo" "22; ca la conjunçión que dize 'et' en el vierbo «et tienpos» muestra que el vierbo 'tienpo' no es ministrador, et así lo scrivió Rabí Abraham bar Hía el spanno[1] ${ }^{63}$. Et así será esto prueva de que erró Rabí Yuçef Camhí ${ }^{64}$ en lo que dixo que "tienpo" es arrimado a "tienpos", comoquier que algunos scrivanos menguaron aquella conjunçión por miedo d'esta contradiçión, así como menguaron otras conjunçiones et ennadieron otras letras.

Et más, que el viesso dixo: «Serán dados en su mano fasta tienpo et

${ }^{55}$ Dn 12,7.

${ }^{56}$ Cf. S. Rosemblatt (ed.), Se`adyah Ga'on: 'Emunôt wě-de`ót, New Haven 1948, p. 298.

${ }^{57}$ Dn 12,11 .

${ }^{58}$ Midraš Rut R. 5,6, y también Midraš Hazita’ II, 9,3.

59 Rosenthal remite al Midraš Leqah Tob, Bamidbar, parasá Balaq, 130a.

${ }^{60}$ Cf. Sanh 98a.

61 Dn 12,7.

62 Dn 7,25.

63 J. Gutmann (ed.), Abraham bar Hiyya: Megilllat ha-mĕgal.leh, Berlin 1924, p. 106, y traducción catalana de J. M. Millás VallicrosA, Barcelona 1929, p. 104.

${ }^{64}$ Cf. supra, nota 30. 
tienpos et medio tienpo" "5, et non "fueron dados Israel en mano de Antíocho fasta mil [94va] et quinientos annos' como lo dizía Rabí Yuçef, porque luego en todo el tienpo de los reyes macabeos o en lo más d'él no fueron Israel quebrantado a los gentiles sino que se ensennoreavan sobre ellos más de lo que fazía ante, et demás que agora no son apremiados a los de Yaván, ca ya tollido es el regno de Yaván. Et más, que el cuento 'mil' no es el mayor de todos los cuentos segund el ebraico como lo dizía Rabí Yuçef, porque el cuento 'diaz mil' es dicho en el ebraico 'revava' o 'ribó' 66 et es mayor que mil.

Otrosí en lo que dixo "medio tienpo" en el caldeo muestra que lo que dize "medio" en el ebraico "ca ha tienpo et tienpos et medio» no es dicho por la meatad de los dos tienpos como ellos dizían, sino por la meatad del un tienpo; et así muestra esto otrosí que los dos tienpos non son desiguales uno a otro como ellos tenían. Et esto porque dixo ençerradamiente «medio tienpo", et otrosí que dixo "et medio" ençeradamente, que quiere dezir "el medio tienpo sabido'. Et más, que non es dicho 'tienpo' ençerradamente, sino por tienpo sabido et poblicado en boca de todo el pueblo, no por tal tienpo como aquel que ellos dixieron. Et más, ¿por qué llamaría el vieso 'dos tienpos' al un tienpo que fue desde la sallida de Egipto fasta el desertamiento del Tenplo primero, seyendo todo un tienpo continuo desde que sallieron de la catividat primera fasta que cayeron en la catividad segunda?

Et más, que lo que scrivió Rabí Sallamón ${ }^{67}$ sobre el vieso que dize: "Desde [94vb] la ora que fue tollido sacrificio" 68 que quier dezir así: 'Desde la ora que fuer tollido el sacrifiçio para dar el enconamiento assolado', como que diz: 'para que den el ídolo en el Tenplo', no es bona glosa porque non fue la entençión en toller el sacrifiçio de cada día para dar el ídolo en su logar. Et más, que sería la palabra de vanidat porque sería oraçión de sujepto sin pedricado, porque non dize qué sería después que passasen días mil et dozientos et noventa desde la ora que fuer tollido el sacrifiçio de cada día et que fuesse dado el ído[lo] en su logar. Et más, que si el vierbo que dize "assolado" fuesse dicho por el ídolo segund ellos dizían, sería mester de ennader una letra condiçional que es dicha en el ebraico ' $h e$ ', la que ata los vierbos en el pedricado de la oraçión para ayuntar la diferençia con el genus para apartar la speçia de aquellas otras speçias, et oviera a dezir: 'el enconamiento que es assolado' en logar de lo que dixo: "Darán el enconamiento assollado"; et assí oviera a dezir: 'el pecado que es asollado' en logar de lo que dixo: «El pecado assollado dar»;

65 Dn 7,25.

${ }^{66}$ Rébabâa, 'diez mil'; rébabobot, ribbót, sus plurales.

${ }^{67}$ Cf. Raši a Dn 12,11.

${ }^{68}$ Dn 12,11 . 
y esto p[ara] departir aquel enconamiento del ídolo que es callado de los otros enconamientos que no son callados, como el puerco que dixieron que ge le levaron para sacrifiçio, o el saçerdote nesçio por quien dixieron [95ra] que es enconamiento ${ }^{69}$. Et esto da a entender que aquel vierbo 'assollado' o 'callado' es predicado en la oraçión et non subjecto como ellos dizían.

Et por ende herró ${ }^{70}$ Rabí Yuçef Cạmhí en lo que scrivió que lo que dize el viesso: "Darán el enconamiento assollado", es dicho por Jhesu Nazareno, que'l pussieron en logar del Tenplo; et que no quier dezir 'assollado' segund primera persona sino 'assollador' segund terçera persona; et que este Jhesu Nazareno fue enconamiento que dio assollamiento et perdiçión a los que creyeron en él. Ca si assí fuesse como dixo Rabí Yuçef dixiera el viesso: 'darán el enconamiento que es assolador', con ennadimiento de la letra ' $h e$ ' condiçional que ata los vierbos como dicho es. Et más, que aquel vierbo 'assollado' no quier dezir segu[n]d el ebraico 'assollador' de todo en todo, porque otros tales vierbos son fallados que non muestran segund terçera perssona sino segund primera persona.

Et más, que lo que dixo Rabí Mossé bar Nahamán ${ }^{11}$ sobre el viesso que dize: "Para dar enconamiento assollado" que quier dezir que el Christo dará el enconamiento para que sea assollado et perdido, es palabra de vanidat porque en la visión quarta misma de Daniel dixo el viesso: "Dessonrarán el sa[n]tuario fuerte et toldrán el sacrifiçio de cada día et darán el enconamiento assollado" ${ }^{72}$, que da a entender segund su glosa que aquellos enemigos que desonrasen el santuario et tolliessen [95rb] el sacrifiçio de cada día, ellos darían el enconamiento para ser assollado; non que el Christo le daría para ser assollado como dizía Rabí Mossé, sino si'l fiziese por medianería de los enemigos que dessonrasen el Tenplo, que ellos darían a los pecadores sus enemigos para ser folladura et assollamiento. Et seguirse ía d'esto segund su glosa que los judíos fueron el enconamiento que avían a ser assollados et desanparados en aquel tienpo que fue tollido el sacrifiçio de cada día, et que aquel tienpo de salvaçión fue a la fin del desertamiento como es provado por sus dichos d'ellos.

Et más, que squiva cossa es a dezir que llamaría el viesso "Ala de enconnamientos" al Tenplo porque era alto como ala de ave ${ }^{73}$ et que es ensalçado et alongado de los enconamientos como lo glossó Rabí Sallamón ${ }^{74}$

${ }^{69}$ Posible referencia a $1 \mathrm{Mac} 1,50$ y 57.

70 Esto es, «erró». En lo comentado luego a Dn 11,31 Yosef Qimhi sigue la opinión de Ibn Ezra en su comentario a Dn 9,25, según indica Rosenthal.

${ }^{71}$ Nahmánides. Rosenthal remite al Sefer ha-Gẻula.

72 Dn 11,31.

${ }^{73}$ Cf. la nota de F. Cantera a este pasaje de Dn 9,27, p. 799 de su ed. de la Biblia.

${ }^{74}$ Raši escribe: "el ala de las abominaciones [...] y sobre una morada alta, entre abominaciones y execración». 
et trasladaron algunos trasladadores segund su manera; mas pareçe que no es lengua de alabança sinon de fealdat, como que es alla ${ }^{75}$ que lleva consigo los enconamientos, o que los allega, o que los encubre so sus alas. Et aunque fuesse ala dicha por 'alteza', que quisiesse dezir 'alteza de los enconamientos', no querrié dezir 'enalçamiento et tollimiento de los enconamientos', mas quería ${ }^{76}$ dezir 'enalçamiento de los enconamientos', ca aquello sería el arrimamiento de la ala que muestra el viesso a los enconamientos.

Et más, que no convernía a dezir que lla [95va] maría el viesso "assollado" al ídolo, sino si fuesse ayuntado a el vierbo 'pecado' o 'enconamiento', o tales vierbos como estos, para que se entendiese que era dicho por el ídolo, así como lo que dixo: "Enconamiento assollado" y «el pecado assollado" "77; et por ende sería guisado segund esto annader en este logar el vierbo 'enconamiento' et dezir: "Sobre alla de enconamientos el enconamiento assollado" ${ }^{78}$; et sería guisado otrosí a dezir: «Et fasta que fin et ta[j]adura corra sobre el enconamiento assollado" ${ }^{79}$. Et más, que si fuere la entençión del viesso que el enconamiento fuesse puesto en el Tenplo, que era ala alta de los enconamientos, fasta que corra fin et tajadura sobre aquel enconamiento assollado, ser[í]a de más la letra ' $v a v$ ' que es conjunción en aquel vierbo que dize: "Et fasta que fin", porque confondría la razón.

Et más, que non conviene a dezir por ninguna guissa que contaría el viesso la pena del pueblo del príncipe que vernía ante que acabase de contar todos sus pecados; ca después que dixo: "Et la çipdat et 1[a] santidat confondrá el pueblo del príncipe que verná" ${ }^{80}$, ca aquello era el pecado del pueblo del príncipe, ¿cómo diría: «Et su stremidat con eslavamiento" ${ }^{81}$, ca aquello tienen que es la pena del pueblo del príncipe, et diría después d'esto: “Fasta que fin d'ela et tajadura et assolamientos" ${ }^{82}$, que aquello era el pecado del pueblo del príncipe; et diría después de aquello: «Creçentará postura a los mu[95vb]chos una selmana, et a la media selmana toldrá sacrificio et ostia. Et sobre ala de enconamientos assollado" ${ }^{83}$, que aquello sería pecado del pueblo del príncipe, et tornaría después d'esto a dezir: «Et fasta que fin et tajadura corra sobre el assollado" ${ }^{84}$, que aquello era pena del pueblo del prínçipe segund ellos tienen? Et más, oviera a dezir segund

\footnotetext{
75 Esto es, «ala», con trueque gráfico.

76 Probable trueque por «querría».

77 Dn 11,31 y 8,13 , respectivamente.

${ }^{78}$ Dn $9,27$.

79 Ibidem.

${ }^{80}$ Dn 9,26.

81 Ibidem.

82 Ibidem.

${ }^{83}$ Dn 9,27 .

84 Ibidem.
} 
esto en esta guissa ${ }^{85}$ : 'Después de las selmanas sessenta et dos será tajado Christo et no á Él, et la çipdat de la santidat cofondrá el pueblo del príncipe que verná. Et creçenterá postura a los muchos una selmana, et a la media selmana toldrá sacrifiçio et ostia. Et sobre alla de enconamientos assollado; et fasta fin de lid tajadura et assollamientos, et su stremidat con eslavamiento, et fasta que fin et tajadura corra sobre el assollado'.

Et más, que es cossa squiva a dezir que el viesso es menguado et que aya mester remiendo, como lo dizen aquellos glossadores que es tal como si dixiesse: 'Selmanas setenta son setenciadas sobre tu pueblo et sobre la cibdat de tu santuario para aver poblamiento, et después d'esto avrán catividad et desertamiento fasta que sea acabado el yerro et conplido el pecado', ca si el omne oviese poder de ennade[r] vierbos en los viessos segund su voluntad trastornaría las palabras de Dios vivo et astragaría el mundo. Y aún los setenta [96ra] annos de la catividat de Babillonia fueron d'estas setenta selmanas en que no fueron Israel ni el Tenplo poblados ni assosegados como ellos dizen; et no convernía que contasse el viesso lo que sería después de setenta selmanas ante que contasse 1[o] que sería en aquellas setenta selmanas, ni que respondiesse el ángel a Daniel respuesta para perdonar los pecados que no avrán fecho nin que los avrán a façer fasta después de quatroçientos et noventa annos, et dende adelante fasta mil et .CCC. et treinta et .VI. annos, non demandando Daniel por ellos en su oraçión perdonamiento ni partimiento.

Et más, que pareçe por los viessos que en el viesso que dize: "Selmanas setenta son setençiadas sobre tu pueblo" ${ }^{86}$, contó en general todos aquellos acaeçimientos et después speçificólos y splanólos en los otros viessos que'l siguen. Et por ende, pues que dixo en aquel viesso primero: «Para aduzir justiçia de siglos" ${ }^{87}$, y splanó en los otros viessos et dixo: "Fasta Christo prínçipe» ${ }^{88}$, et: "Será tajado Christo» ${ }^{89}$, síguese a dezir que por aquel Christo fablava a primero et que sería el Christo en aquellas setenta selmanas et morría, sino que remanesçría su justiçia spiritualmente para los siglos sobre pueblo de Israel.

Et más, que ya dixieron los sabios del Talmud que dixo el viesso: «Será tajado Christo et no á él" ${ }^{90}$, [96rb] por el Christo de linage de Josep que avía a ser matado et que luego después de la su muerte vernía el Christo fijo de David ${ }^{91}$; et síguese d'esto otrosí que ya venido es el Christo.

${ }^{85}$ Da ahora completos Dn $9,26-27$, pero los mezcla y reordena del modo que ha explicado previamente.

${ }^{86}$ Dn 9,24 , al que se aludía también en el párrafo anterior.

87 Ibidem.

${ }^{88}$ Dn 9,25 .

89 Dn 9,26 .

90 Ibidem.

${ }^{91}$ Midraš no localizable. Sobre el Mesías hijo de José, cf. Suk 52a. 
Et más, que no es guisado lo que scrivió Rabeno Çahadia ${ }^{92}$ et assí Rabí Mossé el Egipçiano ${ }^{93}$, que el viesso que dize en Daniel: «Los hijos de los $\mathrm{m}[\mathrm{al}] \mathrm{os}$ de tu pueblo enalçarse [h]an para levantar propheçía et entrepesçarán" ${ }^{94}$, fue dicho esto por Jhesu Nazareno et su conpanna; y esto es porque el contradezidor poderle ía dezir que más guisado sería a esplanar que fue dicho aquel viesso por Rabí Haquiva et sus conpanneros, que tovieron por Christo a Ben Cozeva ${ }^{95}$, ca ellos se enalz[aron] para levantar la propheçía de que dixo el viesso que [avrían] ${ }^{96}$ propheçía para ál tienpo, et que entrepesçaron, ca fueron muertos todos et se perdió la remenbrança de aquel 'Christo' et la su salvaçión del mundo, no como la remenbranca de Jhesu Nazareno et la su salvaçión, que remanesçió et creçentó sienpre. Et si dixieres que no es guissado a splanar aquel viesso por Rabí Haquiva et Ben Cozeva porque ellos fueron después del desertamiento del Tenplo segundo et que aquella propheçía de Daniel no fue sino para el tienpo del Tenplo segundo fasta el conplimiento de las setenta selmanas, [96va] seguirse á otrossí a dezir que la fin del tienpo de las maravillas et la levantança de Migael el ángel, et escapar todo el qui fuere scripto para vida en el Libro ${ }^{97}$, fue otrosí en aquel tienpo.

Et más, que aquel sabio Rabeno Zahadia splanó lo que dixo el viesso: «Después de aquello estará sobre su conpostura tolledor del angustiador» ${ }^{98}$, que aquél fue $\mathrm{M}$ [ath]atías, saçerdote mayor ${ }^{99}$, y esto es verdat; sino que el tienpo más antigo que dixieron ellos de la venida de Jhesu Nazareno es que fue en tienpo del rey [Ya]nay, que fue grant tienpo después de Mathatías, et de Judá et de Jonatán et de Simón, su[s] fijo[s] ${ }^{100}$, de Hyrcano, el fijo de Simón, et de Aristablos, su fijo ${ }^{101}$. Et pues, ¿cómo departería el viesso fecho de Jhesu Nazareno ante del fecho de Mathatías et Él seyendo después d'él muchos annos?

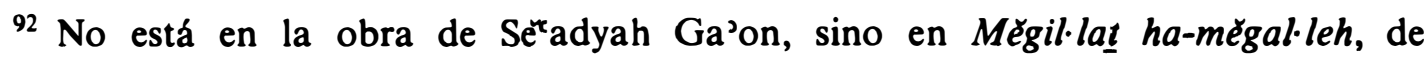
Abraham bar Hiyya, ed. cit, p. 98 (Gutmann).

${ }^{93}$ Maimónides: Carta a los judlos del Yemen, edición y traducción J. TARGarona, Barcelona 1987, parágrafo 10, p. 151.

94 Dn 11,14.

${ }^{95}$ Simeón bar Kohba, líder de la revuelta judía contra Roma de 132-135, fue reconocido como Mesías por R. Aqiba.

96 V.: a vn.

${ }^{97}$ Referencia a Dn 12,1.

98 Dn 11,20.

${ }^{99}$ Cf. Raši a Dn 11,20. Matatías y sus cinco hijos encabezaron la rebelión macabea contra Antíoco IV Epifanes en el 167 a. C.

100 V.: su fijo.

101 V. add. et de Yanay su fijo. Alejandro Janneo, el "Yanay" del texto, hermano y sucesor de Aristóbulo I, reinó desde el 103 a. C. hasta su muerte (76 a. C.). Su reinado supuso una gran prosperidad para su pueblo. 
Et más, que non conviene lo que otros ${ }^{102}$ dixieron que Daniel mis[m]o non entendió la fin del tienpo de la salvaçión, et que no lo descubrió Dios a los ángeles ni a $\mathrm{n}$ [ingu]na creatura ${ }^{103}$. $\mathrm{Ca}$, si esso fuesse, pues ¿cómo juró el ángel por lo que non sabié qué cossa era, et por qué dixo el ángel la fin del tienpo ${ }^{104}$ que no avía a ser sabido, et quál pro avía en scrivirlo en libro, et para qué era mester asconderle, que él se estava ascondido de suyo? Otrosí ¿no'l convernía a dezir que Daniel ençerasse ninguna cossa, sino [96vb] en su vida, no que la çer[ra]sse fasta el tienpo de la fin de la venida del Christo? Et non fue acomendado que çerrasse la fin del tienpo, sino que fue mandado que çerrase las palabras del libro fasta la fin del tienpo, como dixo el viesso: «Et tú, Daniel, çierra las palabras et sella el libro fasta la ora de la fin del tienpo" ${ }^{105}$, et por aquellas palabras dixo el viesso: "Ca çerradas et selladas son las palabras fasta ora de la fin del tienpo" 106; es a catar quáles son aquellas palabras que mandó çerrar.

Et aunque dixiésemos que Daniel a primero no entendía 'la fin del tienpo de la salvaçión', segund que dixo: "Yo oí et no entendí» ${ }^{107}$, evat que lo entendió a postreras quando ge lo esplanaron en el viesso que dize: "Desde la ora que fue tollido el sacrifiçio de cada día» ${ }^{108}$. Et assí scrivió Mariyuday Guaón ${ }^{109}$ ca aquelos ángeles entendían el cuento del tienpo de la fin que muestra el viesso "Tienpo et tienpos et medio" "110 et que Daniel no lo entendió fasta que ge lo splanó el ángel et dixo: "Días mil et dozientos et noventa ${ }^{111}$. Et demás, que conviene a dezir que por lo que no entendía Daniel preguntó et dixo: “¿Qué será la postremería d'estos?» "112, que quiere dezir 'd'estos que son pueblo de la santidat'; ca si esto [97ra] fuesse pregunta por el tienpo de la fin de la salvaçión oviera a dezir: '¿qué cuento es este', o ¿dónde acomençará?, o algunos vierbos tales como este.

\footnotetext{
102 Cf. Ibn Ezra a Dn 11,30.

103 Sanh 94a.

104 Referencia a Dn 12, especialmente 4 y 9.

${ }^{105}$ Dn 12,4.

106 Dn 12,9.

107 Dn $12,8$.

108 Dn $12,11$.

109 En el texto heb., "Mar Yehuday Gaón». Se trata, posiblemente, de Yehuday b. Nahman, gaón de Sura entre 757 y 761, que reforzó el papel central del Talmud babilónico en el judaísmo y se enfrentó a los caraítas. Cf. Y. HorowItz, «Yehudai b. Nahman (Yehudai Gaon)", en Encyclopaedia Judaica, Jerusalem 1971, XVI, cols. 731732. Rosenthal no encuentra la fuente de esta atribución de Alfonso.

110 Dn 7,25.

111 Dn 12,11 .

112 Dn 12,8 .
} 


\section{Glosario}

Abondar (93rb): bastar.

Arrimamiento (95rb): proximidad.

Ayuntar (93ra): añadir.

Catar (96vb): mirar con atención.

Conpanna (92rb): compañía, grupo.

Conpostura (96va): lugar, sitio.

Creçentar (93va): crecer.

Cuento (92rb): cantidad.

Decolgada (92rb): dependiente de.

Enconamiento (94vb): deshonra, impureza.

Ennader (94vb; también Annader, 95va, y Ennadir, 92va): añadir.

Eslavamiento (95vb): inundación.

Evat (96vb): he aquí.

Folladura (92ra): pisoteo.

Frauguamiento (92va): construcción.

Levantança (96va): aparición, surgimiento.

Menguar (94rb): suprimir.

Mester, ser (93va): ser menester.

Ministrador (94rb): servidor.

Paladinamente (93ra): claramente.

Postreras, a (96vb): al final.

Postura (95vb): pacto.

Selmana (92va): semana (leonesismo).

Significança, en (93ra): en sentido figurado.

Soltura (93va): explicación.

Squiva (96rb): errada, equivocada.

Stremidat (95vb): extremo, fin.

Tajadura (95va): devastación.

Toller (92ra): quitar, suprimir.

\section{Epistola segunda}

(Ms. Parma 533, cols. 89a-95b)

Te suplico, querido y respetado sabio R. Mošeh ha-Hazan, tu Dios y tu Salvador te guarden, que prestes atención a lo que está escrito en el Libro de Daniel: Luego of a un santo que hablaba y decía un santo al que estaba hablando: "¿hasta cuándo durará [lo que anuncia] la visión: el sacrificio cotidiano, la iniquidad de desolación, y el santuario y el ejército hollados?» $Y$ me contestó: "hasta dos mil trescientas tardes y mañanas; después será restablecido el santuarion [Dn 8,13-14]. 
Expuso Rabbenu Šèlomoh: ¿Hasta cuándo durará esta visión del sacrificio cotidiano, acerca de la abolición del sacrificio diario y de su sustitución por la iniquidad de desolación? ${ }^{113}$; ciertamente «iniquidad de desolación» es un término para referirse al ídolo, que es silencioso, como una piedra muda. "Y el santuario [wë-qôdes] y el ejército hollados": La waw de wĕ-qôdeš [y el santuario] es superflua, como la que aparece en se paralicen carros [wĕrekeb] y caballos [Sal 76,7]. "Hasta tarde y mañana" es un cálculo numérico de 'ereb bôqer, que se menciona por dos razones: la primera, para que este cálculo se adecue al cálculo mencionado al final del libro: mil doscientos noventa días [Dn 12,11], y la segunda, por cuanto que dijo Gabriel a Daniel: la visión de la tarde y la mañana, de que se ha hablado, es verdadera [Dn 8,26$]$, pues si el significado del cómputo y su fundamento no dependieran de esas palabras, ¿por qué iba a insistir repitiendo "es verdadera»?

'Ereb bôqer, según el cómputo de sus letras, tiene el valor de quinientos setenta y cuatro 144; añadiéndolos a los dos mil trescientos mencionados en ese versículo da un total de dos mil ochocientos setenta y cuatro, y éste es el número de años que hay desde la cautividad en Egipto hasta la venida del Mesías, a saber: doscientos diez de la cautividad de Egipto, cuatrocientos ochenta desde entonces hasta la construcción del Primer Templo, cuatrocientos diez que estuvo en pie, setenta que permaneció destruido y cuatrocientos catorce que estuvo ocupado el Segundo Templo hasta el momento en que fue abandonado el sacrificio diario, pues el sacrificio diario fue abandonado seis años antes de la destrucción [del Templo], lo que da mil quinientos ochenta y cuatro; añadiéndoles mil doscientos noventa, que hay desde el momento en que fue abolido el sacrificio diario hasta la venida del Mesías, resultan dos mil ochocientos setenta y cuatro, como se ha mencionado. Y dijo que, aunque no tenemos una prueba explícita de aquellos seis años, sino que se toman para que este cómputo se adecúe al que se menciona al final del libro, el versículo los llama a esos seis años «media semana", cuando dice: y a la mitad de la semana hará cesar el sacrificio y la oblación [Dn 9,27] de modo que no se complete una semana con ellos ${ }^{115}$.

Algunos añaden la letra waw a la palabra bốqer con el fin de completar esos seis años ${ }^{116}$.

Por tanto, el momento de la abolición del sacrificio diario tendrá lugar al final de la destrucción, y la palabra yamim [días, años] que se menciona al final del libro, cuando dice mil doscientos noventa se debe interpretar en el

\footnotetext{
${ }^{113}$ Cf. nota 17.

$114 c=70, r=200, b=2, b=2, q=100, r=200$; en total, 574.

${ }^{115}$ Cf. Raši a Dn 9,26; Raši aclara: "y a la mitad de la semana» romperá su pacto. 116 Cf. nota 24.
} 
mismo sentido que en el versículo: un año durará su derecho de rescate [Lv 25,29] y en anualmente [Jue 11,49] ${ }^{117}$.

Por tanto, ya se han cumplido los dos tiempos y medio que se mencionan en el versículo que dice: dentro de un tiempo, dos tiempos y medio [Dn 12,7], pues el vocablo «dentro de un tiempo" [lě-mô‘ $e \underline{d}$ ] es auxiliar, como en el tiempo [lë-mốed] del mes de Abib [Ex 23,15] ${ }^{118}$. El cómputo es: dos tiempos y la mitad de dos tiempos, es decir, un tiempo: [un tiempo] son los cuatrocientos ochenta [años que hay] desde el éxodo hasta [la construcción] del Primer Templo y el segundo tiempo son los cuatrocientos diez [años] que pasaron desde la construcción del Primer Templo hasta su destrucción, luego esos dos tiempos [suman un total de] ochocientos noventa; como su mitad es cuatrocientos cuarenta y cinco, el total serán mil trescientos treinta y cinco [años] ${ }^{119}$.

R. Yosef Qimhi explicó 120: dentro de un tiempo, dos tiempos y medio [Dn 12,7] es lo que está escrito: por un tiempo, dos tiempos y medio tiempo [Dn 7,25] y es como decir Rey de Reyes [Ez 26,7] o Príncipe de príncipes [Dn 8,25], es decir, el mayor de todos los cómputos, que es mil, y la mitad de mil, es decir, mil quinientos años. Se cuenta desde el reinado de Antíoco ${ }^{121}$, rey de Grecia, que tuvo lugar hacia la mitad de la época del Segundo Templo, después de doscientos diez años; si los añades a los años del exilio, que son mil doscientos noventa, tendrás mil quinientos.

En mi opinión, no se puede decir que el versículo mencione el número de años o el número de días de algo sin mencionar explícitamente el comienzo exacto de ese cómputo, y, ¿cómo va a ser el comienzo del cómputo de mañana y tarde dos mil trescientos desde el destierro en Egipto, si el destierro en Egipto no aparece nombrado allí?; más aún comenzando el cómputo de "un tiempo, dos tiempos y medio», según dicen ellos, por otro comienzo, que es la salida de Egipto. Según R. Yosef Qimhi, comienza con el inicio del reinado de Antíoco, pero no se menciona en el versículo ni el destierro en Egipto ni la salida del destierro de Egipto ni el reinado de Antíoco.

Más aún, ¿cómo puede ser que una parte del cómputo, dos mil trescientos años, se mencione explícitamente y la otra parte mediante interpretación alegórica y cómputo de letras, a partir de las letras de 'ereb bóqer, que es, según ellos dicen, quinientos setenta y cuatro?; ¿por qué no aparece todo ello mencionado en forma alegórica o todo ello de modo explícito? Incluso si el significado alegórico, según el cómputo de letras, fuera como ellos dijeron, no hay base para formular esa cifra de dos mil ochocientos setenta

\footnotetext{
117 Cf. nota 26.

118 Cf. nota 28.

119 Cf. nota 29.

120 Cf. nota 30.

${ }^{121}$ Cf. nota 34.
} 
y cuatro años, y no se puede saber si el cómputo es de años, de meses, de días, de horas, o de años o de sabáticos. Y aunque dijeras que las palabras 'ereb bôqer valen a la vez para las dos cosas, para expresar el cómputo según el orden de las letras en el alfabeto y para deducir el cómputo del contexto de las palabras en la lengua hebrea, según esto el cómputo se referiría a días, pues el día tiene tarde y mañana, y no a años, como dicen ellos; y siendo así, ya ha pasado el tiempo [de la venida del Mesías], pues esto es lo que se deduce de lo que ellos dicen.

Además, el versículo en el que se dice: y la visión referente a la tarde y a la mañana, de que se ha hablado, es verdad [Dn 8,26] da a entender claramente que no se trata ni de interpretación alegórica ni de cómputo de letras, pues si así fuera, el versículo tendría que decir lo contrario de lo que dice, y diría: "la visión referente a la tarde y a la mañana, de que se ha hablado, no es verdad", pues el significado literal es la primera acepción [que hay] en las palabras del profeta, y cuando la palabra no sea entendida en su acepción literal será falsa; y no es preciso decir "es verdad" cuando se refiere a la primera acepción que se deduce del versículo; pero se dice «es verdad" queriendo decir que es verdad en su sentido literal, que no hay en él significados ocultos, y que no es una metáfora o una comparación con otra cosa, en cuyo caso necesitaría una interpretación, como la necesitan las otras palabras que se mencionan en esta profecía, como cuando dice: $E l$ carnero dotado de dos cuernos que has visto son los reyes de Media y Persia, $y$ el macho cabrio es el rey de Grecia [Dn 8,20-21]. Y también aclara lo que dice acerca del cuerno del macho cabrío: y creció hasta el ejército de los cielos derribando por tierra parte del ejército y de las estrellas, a las que holló [Dn 8,10], y dice para explicarlo: surgirá un rey insolente y experto en astucias; su potencia será vigorosa, mas no por su propia potencia; verificará destrucciones prodigiosas, prosperará en lo que haga y exterminará a los poderosos y al pueblo de los santos [Dn 8,23-24].

Y puesto que "tarde y mañana" se refiere a un día, como está dicho: $Y$ hubo tarde y hubo mañana, día primero [Gn 1,5], y que «tarde» está unido a "mañana», pues está dicho: al anochecer, al caer ${ }^{122}$ el día [Prov 7,9], y que alguien podría pensar que, del mismo modo que "días" [yamîm] equivale a "año", así "tarde y mañana" está dicho alegóricamente por "año» o por otro espacio de tiempo, o por otra cosa -igual que otras palabras de la profecía son alegorías de otras cosas-, por todo ello el versículo lo explica diciendo "es verdad", es decir, que "tarde y mañana" es verdad en su auténtico sentido literal, y si tuviera otra interpretación o si fuera una parábola o una metáfora o un significado alegórico, el versículo diría: «no es verdad", indicando que no es verdad en su sentido literal, pues si precisara de interpretación, o se callaría o no mencionaría en el versículo

122 En heb. bé-`ereb yóm. 
"es verdad", como no se mencionó con respecto a las otras palabras. Está escrito en el tratado talmúdico [Megil.lâ] ${ }^{123}$ : "Si es verdad, no es una parábola, y si es una parábola, no es verdad». Y dijeron: «La Torah utilizó la hipérbole, los profetas utilizaron la hipérbole y los sabios utilizaron la hipérbole» ${ }^{124}$, es decir, que no es verdad al pie de la letra, igual que había metáforas y parábolas para otras cosas, así dijeron también: «esta parábola no es nada", queriendo decir que no es verdad en su sentido literal, que por eso es una parábola y un enigma; y puesto que dice el versículo "es verdad", eso demuestra sin lugar a dudas que no es una parábola ni ninguna alegoría. $\mathrm{Y}$ además, ellos mismos reconocen no tener una prueba evidente de esos seis años en los que dijeron que el sacrificio diario fue abandonado antes de la destrucción, e incluso en el Seder ha-Qabbalâ está escrito lo contrario, que el sacrificio diario fue abandonado mil doscientos noventa días antes de la destrucción, pues está dicho: $Y$ desde el tiempo en que sea abolido el sacrificio diario... (pasarán mil doscientos noventa días) [Dn 12,11], que son los tres años y medio de los que dice el versículo: y $a$ la mitad de la semana hará cesar el sacrificio y la oblación [Dn 9,27] ${ }^{125}$, y, según esto, el tiempo [mesiánico] llegaría al final de la destrucción.

Además, el término yamîm no significa 'muchos años' en lengua hebrea, según su sentido literal, como dicen ellos, sino que significa 'muchos días' o 'un año', que es el ciclo de los días según sus características y sus cantidades; como está dicho: hasta cumplirse el año de su venta; un año [yamîm] durará su derecho de rescate [ $\mathrm{Lv} 25,29]$ y asi: anualmente [mi-yamim yamimâ] [Juec 11,40], es decir, 'de año a año'. Y, así, escribió R. Yonah ibn Yanāh que yamim es el plural de yôm [día] o, lo que es lo mismo, 'un año', y su plural ${ }^{126}$ debería ser yermimim por analogía con témimim ${ }^{127}$, que es el plural de tamim ${ }^{128}$. También R. Abraham ben Ezra escribió que cuando se nombra yamim, sin que se indique la cantidad, equivale a un año ${ }^{129}$, y que los mil doscientos noventa días mencionados en la profecía de Daniel son realmente días y no años ${ }^{130}$. Y es lo mismo que está escrito en Eliyahu Rabbâ: “'un tiempo' es un año, 'dos tiempos' son dos años, y 'medio tiempo' es medio año, lo que supone tres años y medio" ${ }^{131}$. Y nuestro maestro Se`adyah, de bendita memoria, explicó que [los versículos que

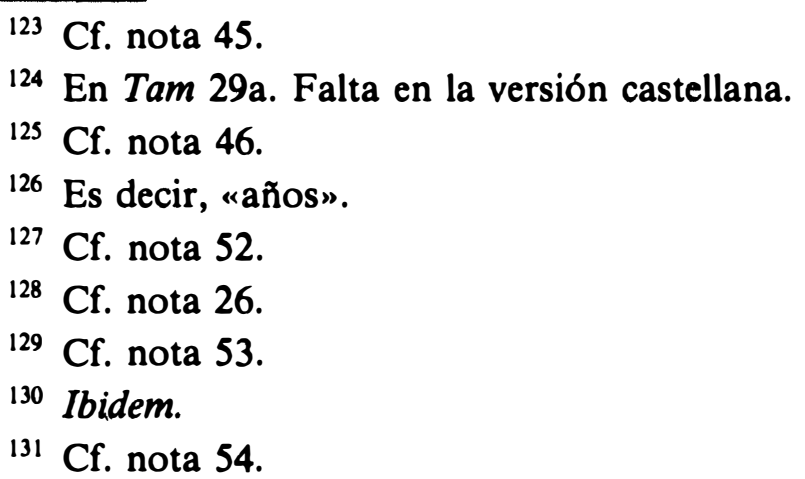


dicen] por un tiempo, dos tiempos y medio tiempo [Dn 7,25] y dentro de un tiempo, dos tiempos y medio [Dn 12,7] son el cómputo mencionado al final del libro: mil doscientos noventa días ${ }^{132}$. Y está escrito en el Midraš de Rut: «esos días de más, ¿qué son? Son los cuarenta y cinco días en los que el Salvador permanecerá oculto" "133; otros dijeron que son los cuarenta y cinco días que van desde que murió el Mesías, hijo de José, hasta la venida del Mesías, hijo de David ${ }^{134}$.

Y así Elías, R. Aqiba, R. Yehošúa b. Leví, Rab y los grandes maestros tannaítas y amoraítas fijaron para la venida del Mesías unas fechas concretas que ya se han consumido y han pasado ${ }^{135}$, y no habrían podido decir esto si hubieran entendido el término yamîm en el sentido de 'años', pues en aquella época todavía no habían pasado mil doscientos noventa años desde el momento en que el sacrificio diario había sido abolido, y no vale decir que los judíos tienen ahora más conocimiento de la lengua hebrea del que tenían los sabios talmudistas, que estaban más próximos al tiempo de los profetas y de quienes viene la tradición que está ahora en manos de éstos.

Además, el término lě-mốed [por un tiempo] no es auxiliar, como decían aquellos comentaristas, sino que es como en el versículo: y serán entregados en su poder por un tiempo ['ad-'iddan] dos tiempos y medio tiempo [Dn 7,25], y la letra waw que aparece en la palabra wé-ciddanîn [y dos tiempos] prueba que el término lë-mô‘ ed no es auxiliar, como ellos decían. Y lo mismo escribió R. Abraham bar Hiyya: que esta letra waw que hay en la palabra wé-iddanin es una prueba de la falta de yuxtaposición ${ }^{136}$. Así pues, esto es una prueba de que R. Yosef Qimhi se equivocó cuando dijo que $m \hat{o}^{\wedge} e \underline{d}$ está yuxtapuesto a mốădim e ciddan a 'iddanin ${ }^{137}$, puesto que algunos comentaristas quitaron ese waw en la expresión 'ereb bôqer.

Además, el versículo dice: $y$ serán entregados en su poder por un tiempo, dos tiempos y medio tiempo, pero Israel no fue entregado en poder de Antíoco, como explicó R. Yosef, hasta mil quinientos años, pues luego, durante toda la época del reinado de la dinastía hasmonea, o en la mayor parte, Israel no estuvo sometido a las naciones gentiles; por el contrario, las dominó más de lo que las había dominado nunca, y además, en ese momento, no estaba sometido a Grecia, pues ya había desaparecido el reino griego. Además, el cómpunto "mil» no es el mayor de todos los cómputos en lengua hebrea, como decía R. Yosef, que éste era el mayor de

\footnotetext{
${ }^{132}$ Cf. nota 56.

133 Cf. nota 58.

134 Cf. nota 59.

135 Cf. nota 60.

136 Cf. nota 63.

137 Cf. nota 30.
} 
todos los cómputos, sino que el cómputo rĕbabâ [diez mil] es mayor que mil.

Lo mismo cuando dice: y medio tiempo [Dn 9,27] prueba que la palabra $y$ medio en el versículo por un tiempo, dos tiempos y medio [Dn 12,7] no se refiere a la mitad de los dos tiempos, como decían ellos, sino a la mitad de un tiempo, y, según esto, se demuestra también que los dos tiempos no son diferentes uno de otro, como pretendían ellos, y por esto es por lo que dice: $y$ medio tiempo con un sentido oculto, y por lo que dice $y$ medio con un sentido oculto, queriendo decir: la mitad del tiempo ya sabido, y lo mismo, dice tiempo con un sentido oculto, refiriéndose al tiempo conocido y sabido por todo el pueblo, no por un tiempo como el que ellos dicen; además, ¿por qué iba a llamar el versículo dos tiempos al tiempo único que va desde la salida de Egipto hasta la destrucción del Primer Templo, habiendo un solo tiempo desde que salieron del primer cautiverio hasta que cayeron en el segundo cautiverio?

Y además, que lo que escribió nuestro maestro Šělomoh acerca del versículo: desde el tiempo en que sea abolido el sacrificio perpetuo [Dn 12,11], cuya explicación es: desde el tiempo en que sea abolido el sacrificio perpetuo para que se establezca la abominación desoladora ${ }^{138}$, quiere decir: para que sea colocada en el templo la imagen idolátrica, que es desolación y como piedra muda, o [cuando dice] que el lamed de la palabra wě-lațet equivale a la partícula min, como dijeron otros ${ }^{139}$, no es así en absoluto, pues el lamed en todas partes se opone a min, según los gramáticos hebreos ${ }^{140}$; pues si su significado fuera el de 'para poner', el waw sería superfluo e ilógico; más aún, la frase sería incorrecta y equívoca, pues sería una frase con sujeto pero sin predicado, pues no dice qué ocurrirá después de que pasen los mil doscientos noventa días, desde el momento en que sea abolido el sacrificio perpetuo y se establezca la abominación desoladora [en su lugar mil doscientos noventa días] [Dn 12,11]; y más, que el asunto sería falso por sí mismo pues la intención no era abolir el sacrificio diario para poner en su lugar la abominación; y además, que si šômem o měsômem [desolador, desolado] fueran calificativos del ídolo, como decían ellos, tendrían que llevar añadida una hê especial que une las palabras en el sujeto de la oración para asociar lo que es de distinta categoría y para distinguir una especie de las otras especies, y tendría que decir «la abominación desoladora» en lugar de decir

138 Cf. nota. 67.

139 Cf. M. WILENSKy (ed.), Yonah ibn Ŷanah: Sefer ha-riqmah, s. 1. 1929-1931, pp. 55 ss.: "y está [el lamed] por min»; W. BACHER, Yonah ibn Ŷanah: Sefer hasorasim, p. 265: «la mem y la nun [...] están en lugar del lamed prefijado».

140 Cf. David Qimhi a 2 Cr 1,13, y B. KLAR (ed.), Moseh b. Isaac de Londres: Sefer ha soham, Jerusalem 1946, p. 11; W. BACHER (ed.), Yosef Qimhi: Sefer ha-zikkaron, Berlin 1888, p. 5. 
"y pondrán la abominación que es desoladora»; y del mismo modo, tendría que decir: "el pecado desolador" en lugar de decir "el pecado es desolador" [Dn 8,13$]^{141}$, y esto es igual que: el hombre más delicado entre vosotros [Deut 28,54] y que: por el asunto del dinero devuelto en nuestros costales [Gn 43,18] ${ }^{142}$, y no dice "el hombre [es] delicado entre vosotros" ni "el dinero es devuelto en vuestros costales", sin he en las palabras rek y šab, como dice en "la abominación [es] desoladora" y "el pecado [es] desolador", sin hê, y esto quiere decir que esos dos términos, šômem y měšômem, son predicados de la oración y no sujetos, como decían ellos.

Por eso R. Yosef Qimhi cometió un error al decir que el versículo: establecerán la abominación desoladora [Dn 11,31] se refiere a Jesús el Nazareno, al cual pusieron en lugar del templo ${ }^{143}$ y que měšômem es una forma activa de un verbo cuadrilítero ${ }^{144}$ y que ese Jesús Nazareno fue una abominación que causó desolación a los que creyeron en él; pues si fuera como decía R. Yosef, el versículo tendría que decir: "y se establezca la abominación que es desoladora», con la adición de la hê unitiva, como ya he mencionado. $\mathrm{Y}$ además, que měsômem no es forzosamente un verbo activo, como él dice, sino que puede ser estativo ${ }^{145}$, como en el versículo: $y$ me senté desolado... y yo permaneci sentado desolado [Esd 9,3-4]. Y además, el versículo dice abominación desolada ${ }^{146}$ [šômem] [Dn 12,11] y la transgresión desolada [šômem] [Dn 8,13], frente a lo que dijo: la abominación desolada ]měšômem] [Dn 11,31], [ala de] abominaciones, la abominación desolada [měšomem] [Dn 9,27], y eso es una prueba de que tanto esas formas como la forma šômem son estativas.

Y del mismo modo, lo que dijo R. Mošeh bar Naḩman ${ }^{147}$ acerca del versículo: y se establezca la abominación desolada [šômem] [Dn 12,11], que quiere decir que el Mesías pondrá el ídolo para que sea devastado y perezca, es incorrecto y absurdo, porque en la misma visión cuarta de Daniel se dice: profanarán el santuario, la fortaleza, abolirán el sacrificio perpetuo y establecerán la abominación desolada [měšômem] [Dn 11,31] [lo que quiere decir] que aquellos enemigos que profanen el santuario y que supriman el sacrificio diario serán los que pongan la abominación para ser

141 Los dos términos, con artículo en el primer caso, y el segundo término, sin artículo en el segundo caso, que es como aparece en el versículo. Cf. Pes 49b.

142 En heb.: ha-'is ha-rak y ha-kesef ha-sab, con artículo en los dos casos.

${ }^{143}$ Falta en lo conservado del Sefer ha-Berit.

$144 \mathrm{Y}$ debe traducirse, por consiguiente, como «desolador», "que causa desolación».

145 También David Qimbi escribe: "y también puede ser estativo». Cf. su Sefer hasorastim, sobre: 5 mm.

146 Traducimos en todos los ejemplos que siguen los dos participios, šômem y mésômem, en su forma estativa, siguiendo la argumentación del autor.

147 Cf. nota 71. 
desolada, no que el Mesías será el que la ponga para ser desolada, como decía R. Mošeh, sino que eso será hecho por medio de los enemigos que profanan el santuario y que abolen el sacrificio diario, pues ellos darán a sus enemigos, los pecadores, a la holladura y a la desolación. Así pues, de aquí se deduce, según su comentario, que los judíos son la abominación, que estaban destinados a ser desolados y abandonados en aquel tiempo en que fue abolido el sacrificio diario y que aquel tiempo (mesiánico) llegó al final de la destrucción, como se concluye de lo que dicen ellos.

Y además, que es tergiversar las cosas el decir que el versículo llama al Templo ala de abominaciones [Dn 9,27] porque es tan alto como ala de ave, y que está elevado y alejado de los ídolos, como comentó nuestro maestro Š̌lomoh ${ }^{148}$; pero me parece a mí que no es ésta una expresión de alabanza, sino de vituperio, pues es un ala que lleva consigo a las abominaciones o que las asocia, mediante la palabra kĕnufeya' ${ }^{149}$, o las encubre bajo sus alas. Y aunque "ala" fuese dicho por 'elevación' y su significado fuera 'elevación de las abominaciones', no querría decir 'grandeza de las abominaciones o elevación de las abominaciones’ por estar lejos de ellas, sino 'elevación de las abominaciones y su ensalzamiento', pues ésa es la unión del ala con las abominaciones, como demuestra el versículo.

Y además, no conviene decir que el versículo llame měšômem o šômem al ídolo si no va unido con esos términos "pecado" o "abominación" o cosa semejante, para que se comprenda que se refiere a la idolatría como "abominación desoladora", la abominación desoladora [Dn 11,31] y la transgresión desoladora [Dn 8,13], y por eso es apropiado, según esto, añadir aquí la palabra "abominación» y decir: "sobre el ala de las abominaciones, la abominación desoladora», y sería apropiado decir también "hasta que el aniquilamiento decretado se derrame sobre la abominación devastadora". Y además, que si siquiera decir que el ídolo, «la abominación desoladora», estará puesto en el Templo, que es "ala alta de las abominaciones", hasta que el aniquilamiento decretado se derrame [Dn 9,27] sobre esa abominación desoladora, la letra waw en la palabra wě-cad sería superflua, ilógica y sólo llevaría a equívocos.

Y además, que no conviene en modo alguno decir que el versículo cuente el castigo del pueblo del príncipe que ha de venir [Dn 9,26] antes de terminar de enumerar todos sus pecados, pues después de decir: $y$ será destruida la ciudad y el santuario del príncipe que ha de venir [Dn 9,26] -lo cual es el pecado del pueblo del príncipe que había de venir-, ¿cómo iba a decir: y su fin será por medio de la inundación [Dn 9,27] -lo cual es el castigo del pueblo del príncipe, según explicaron ellos- y a decir después:

148 Cf. nota 74.

149 Según Raši, «asambleas populares de gentiles». Establece una asociación entre kanaf, 'ala', y kěnufeya', 'asamblea de gentiles'. 
y hasta el final de la guerra están decretadas desolaciones [Dn 9,27] -que es el castigo del pueblo del príncipe - y a decir a continuación: y concertará firme alianza con muchos durante una semana, y a la mitad de la semana hará cesar el sacrificio y la oblación y sobre el ala de las abominaciones [vendrá] el desolador [Dn 9,27] - que es el pecado del pueblo del príncipe-, y a volver después a decir: y hasta que el aniquilamiento decretado se derrame sobre el devastador [Dn 9,27] —que es el castigo del pueblo del príncipe, según ellos dijeron? Tendría que decir, más bien, según esto: «Y después de las sesenta y dos semanas será muerto el Mesías, y nada tendrá, y será destruida la ciudad y el santuario del pueblo del príncipe que ha de venir, y concertará firme alianza con muchos durante una semana, y a la mitad de la semana hará cesar el sacrificio y la oblación, y sobre el ala de las abominaciones [vendrá] el desolador y hasta el fin habrá guerra, devastación decretada, y su fin será por medio de una inundación hasta que el aniquilamiento decretado se derrame sobre el devastador».

Y además, sería un gran error decir que el versículo está incompleto y cortado, como dicen algunos comentaristas, y que es como si dijera: Setenta semanas han sido decretadas sobre tu pueblo y sobre tu ciudad santa [Dn 9,24] para que esté poblada, y después de esto tendrán exilio y destrucción hasta el aniquilamiento decretado [Dn 9,27] de la transgresión y cancelar los pecados [Dn 9,24], como dijo R. Yosef, como si dijera: Después de que se cumplan las setenta semanas decretadas sobre tu pueblo y tu ciudad santa para poner fin a la transgresión [Dn 9,24], pues si el hombre pudiera añadir palabras a su voluntad alteraría las palabras del Dios vivo, exterminaría el mundo, blasfemaría e injuriaría. $Y$ he aquí que los setenta años del reino de Babilonia son parte de esas setenta semanas en que no estuvieron ni Israel ni el Templo poblados, como ellos dicen, y no parece adecuado que el versículo cuente lo que iba a ocurrir después de las setenta semanas antes de contar lo que ocurriría en esas setenta semanas, ni que el ángel diera a Daniel la respuesta para que se perdonaran los pecados que ellos no habían cometido nunca, y que no los habrían de cometer hasta después de cuatrocientos noventa años, y a partir de ahí hasta mil trescientos treinta y seis años, y que no hubiera pedido Daniel el perdón y la expiación de ellos en su oración.

Y además, parece deducirse del pasaje que en el versículo: setenta semanas han sido decretadas sobre tu pueblo [Dn 9,24] contó todos aquellos sucesos en general y, después, los especificó y los explicó en los versículos siguientes. $\mathrm{Y}$ por eso, puesto que dijo en aquel primer versículo para traer justicia eterna [Dn 9,24] y comentó en los versículos siguientes y dijo: hasta el príncipe Mesías [Dn 9,25] y será muerto el Mesías [Dn 9,26], hay que deducir que de ese Mesías hablaba al comienzo, y que llegaría el Mesías en aquellas setenta semanas, y que moriría, pero que quedaría su justicia 
eterna sobre el pueblo de Israel, como está dicho de él: para traer justicia eterna [Dn 9,24].

Y más, que ya dijeron los sabios de bendita memoria que se dice será muerto el Mesías y no tendrá nada [Dn 9,26] por el Mesías hijo de José, y que inmediatamente después de su muerte vendrá el Mesías hijo de David ${ }^{150}$, y de ahí se concluye, también, que el Mesías ya ha venido.

Y más, que no es correcto lo que escribieron Rabbi Sěcadyah ${ }^{151}$ y Rabbenu Mošeh ben Maimon, que el versículo en que se dice: $e$ hijos violentos de tu pueblo se rebelarán para que se cumpla la visión, pero caerán [Dn 11,14] se refiere a Jesús Nazareno y su grupo ${ }^{152}$; pero el objetante podría decir que sería más correcto explicar que ese versículo se refiere a R. Aqiba y sus compañeros, que apoyaron a Ben Koziba' como si fuera el rey Mesías, pues ellos se habían rebelado para que se cumpliera la visión a la que se refiere el versículo, en el cual está escrito que todavía habría una profecía en un tiempo fijado, y cayeron, pues todos ellos fueron muertos y se desvaneció el recuerdo de ese Mesías, y desapareció su salvación del mundo, lo contrario que con Jesús Nazareno y su salvación, que permaneció y aumentó siempre. Y quizás digas que no es adecuado aplicar ese versículo a R. Aqiba y a Ben Koziba', porque ellos vivieron después de la destrucción del Segundo Templo, y que la profecía de Daniel sólo se refería a la época del Segundo Templo, hasta que se cumplieron las setenta semanas, entonces habría forzosamente que decir que el final del tiempo de los milagros, del surgimiento de Miguel y de la liberación de todo aquel que estuviera inscrito para vivir en el Libro ${ }^{153}$, también ocurrió en esa época.

Y además, aquel Gaon ${ }^{154}$ explicó lo que está escrito después de esto: En su lugar surgirá el que enviará un opresor [Dn 11,20], que fue el Sumo Sacerdote Matatías ${ }^{155}$, y es verdad, sólo que la fecha más antigua que ellos dieron para la venida de Jesús Nazareno era para la época del rey Janneo ${ }^{156}$, mucho tiempo después de Matatías: todos los días del reinado de Matatías, de Judas [Macabeo], de Jonatán y de Simón, su[s] hijo[s], de Hircano, hijo de Simón, y de su hijo Aristóbulo y de su hijo Janneo; y siendo así, ¿cómo iba a contar el versículo el asunto de Jesús Nazareno antes que el de Matatías, si fue muchos años después?

Y además, no es correcto lo que dijeron otros, que el mismo Daniel no

\footnotetext{
150 Cf. nota 91 .

151 Cf. nota 92.

152 Cf. nota 93.

153 Cf. nota 97.

154 Es decir, Sa'adyah ha-Ga’on.

155 Cf. nota 99.

156 Cf. nota 101.
} 
comprendió el fin de los tiempos ${ }^{157}$ y que el Santo, bendito sea, no lo reveló a los ángeles del servicio ${ }^{158}$ ni a ninguna otra criatura, pues si así fuera, ¿cómo iba a jurar el ángel por lo que no sabía qué era?, y ¿por qué iba a mencionar el ángel el final de los tiempos, si esto no debía ser sabido?, y ¿qué provecho había en escribirlo y qué necesidad había de ocultarlo? Y, del mismo modo, no es posible que Daniel sellara ninguna palabra más que en su visión ${ }^{159}$, no que lo ocultara hasta el final de los tiempos de la venida del Mesías; y no se le ordenó que ocultara el final de los tiempos, sino que se le ordenó que mantuviera ocultas las palabras del Libro hasta el final de los tiempos, como está escrito: $Y$ tú, Daniel, mantén acultas estas palabras y sella el libro hasta el tiempo final [Dn 12,4], y de ellas dice: Pues estas palabras han de permanecer cerradas y selladas hasta el tiempo final [Dn 12,9].

Y aunque dijéramos que, al principio, Daniel no comprendía el momento del tiempo final, como dijo: $Y$ yo oí, mas no comprendi [Dn 12,8], ciertamente lo entendió al final, cuando se le explicó en el versículo: $Y$ desde el tiempo en que sea abolido el sacrificio perpetuo... [Dn 12,11]. Y así escribió Mar Yehuday Gaon ${ }^{160}$ que aquellos ángeles entendían el cómputo del tiempo final, de un tiempo, dos tiempos y medio [Dn 12,7], y que Daniel no lo entendía hasta que el ángel se lo explicó y dijo: mil doscientos noventa días ${ }^{161}$. Por esto es apropiado decir que Daniel preguntó acerca de lo que no comprendía, y dijo: ¿Cuál será el final de éstos? [Dn 12,8], y si fuera ésta una pregunata sobre el final de los tiempos, habría dicho: ¿cuál es ese número?, o ¿desde dónde comienza?, o algo perecido, pero lo que dijo: ¿cuál será el final de éstos? [Dn 12,8] se parece al versículo: Veré cuál es el fin de ellos [Deut 32,30], cuya explicación es: “¿qué fin tendrán ellos?» ${ }^{162}$, es decir: “¿cuál será el final de éstos, que son un pueblo santo?»

AMPARO ALBA CECILIA

CARLOS SAINZ DE LA MAZA

Universidad Complutense. Madrid

\footnotetext{
${ }^{157}$ Cf. nota 102.

${ }^{158} \mathrm{Cf}$. nota 103.

159 Sic. En V.: «su vida». Posible error en la edición del texto hebreo.

160 Cf. nota 109.

161 Cf. Dn 12,11.

162 Cf. Raši ad loc.: «¿Qué provecho hay para ellos en su final?». Nótese la diferencia en los finales de ambas versiones de la epístola.
} 